\title{
The Bern Convention and Its Widened Steps *
}

$T^{\mathrm{h}} \mathrm{ros}$ his Year of 1994 has been an important one for Nature conservation. Two new legal international instruments have come into force: the EEC 'Habitats Directive' and the Biodiversity Convention. The future of the Council of Europe's Bern Convention will be greatly influenced by how other treaties will be implemented, as the three instruments share the same 'global' approach to solving environmental conservation and development problems. Although the geographical coverage of the three treaties (EEC, World, and Europe, respectively) is not the same, it is clear that there is a need to coordinate the way in which they will work and interconnect.

\section{EEC 'Habitats Directive'}

Of this the full name is Council Directive 92/43/EEC of 21 May 1992 on the Conservation of Natural Habitats and of Wild Fauna and Flora. The Habitats Directive was adopted in 1992, but it gave the European Union governments two years to adapt their laws, regulations, and administrative provisions, so as to comply with the obligations in the Directive. The EEC has been a party to the Bern Convention since 1982. As all other parties, it had the obligation to review its internal legislation so as to bring it in line with the terms of the Convention. It took the EEC ten long years to do so, but this delay has, in the end, provided a good opportunity, as the Habitats Directive is, in many and different ways, more modern and complete than the original Bern Convention. Especially has it given a more sound legal solution to habitat conservation by listing both natural habitats and species requiring designation of special areas for conservation.

\section{The Convention on Biological Diversity}

This convention was adopted in Rio in 1992 and came into force three days before 1994 began. It is the first world-wide convention that, much as the Bern Convention does in Europe, is not limited to covering just a particular conservation problem (such as trade in endangered species, by CITES), or a particular habitat-type (such as wetlands by the Ramsar Convention), or a group of species (such as migratory species by the Bonn Convention). It is designed to cover a wide variety of both conservation and development issues.

The Convention on Biological Diversity is made up of both old and new concepts. It contains many ideas and approaches that were present in more 'classical' Nature conservation conventions (such as sustainable use of resources, preservation of endangered life-forms and habitats, control of activities potentially threatening biological diversity, guiding of development practices, etc.). One particularly interesting novelty is the extension of conservation to non-wild species, such as threatened varieties of crop species, of cultivars, and of rare livestock.

The Convention on Biological Diversity has introduced three new 'chapters' which were absent from other Nature conservation conventions:

1) access to and transfer of genetic resources (Art. 15);

2) Access to and transfer of technology, including biotechnology (Arts 16 and 19), and

3) financial mechanisms to ensure solidarity with developing countries (Arts 20 and 21).

* Adapted from Naturopa-Newsletter. - Ed.

\section{A New Role for the Bern Convention}

In the last 12 years the Bern Convention has extended its membership to cover three-quarters of the states of Europe. It can contribute to implement regionally some aspects of the Convention on Biological Diversity, though it is clear that a part of the obligations of that Convention can only be dealt with on a world scale (for instance: access to and transfer of genetic resources and technology, and the financial mechanisms to ensure solidarity). However, other aspects of the Convention on Biological Diversity could be best dealt with at the regional level, including the following:

cooperation (Art. 5), including exchange of information (Art. 17) and technical and scientific cooperation (Art. 18);

- in situ (Art. 8) and ex situ (Art. 9) conservation of biodiversity, including the identification and monitoring of their components (Art. 7);

- conservation and sustainable use of biodiversity (Art. 6 ), including identification and control of processes with potentially adverse impact on biodiversity (Articles 7 and 14); and

- research, training, public education, and awareness (Articles 12 and 13).

But this is not enough: the Bern Convention must be sufficiently daring to extend the new concepts and philosophy of the Habitats Directive to the whole of Europe. This was partly started in 1989 , when a series of recommendations of the Standing Committee to the convention enlarged the interpretation of the habitats provisions of the convention. Yet this needs to be further developed by, for instance:

1) adopting listing procedures for threatened natural habitats and species requiring special habitat conservation measures, as well as developing a pan-European network of protected areas (the extension of the network Natura 2000 to the whole of Europe could be contemplated as a coordinated effort with the European Union); and

2) developing ways to deal with conservation issues outside protected areas, including landscape values' protection. This could be achieved by further developing Recommendation Nr 25 (1991) of the Standing Committee on the conservation of natural areas outside protected areas proper.

Other tasks ahead are:

3) identification and control of processes with potentially adverse impacts on Nature, including the listing of such activities (this could be inserted into the Convention by interpreting the obligations of Art. 3, paragraph 2 of the Convention, which reads 'Each Contracting Party undertakes, in its planning and development policies and its measures against pollution, to have regard to the conservation of wild flora and fauna'. Under this general topic of planning and development policies, many precise subjects could be developed, such as the impact of public works (dams, roads, and railways) on environment, management of special areas such as coastal areas, promotion of 'wise' use of agricultural practices, and how to influence activities such as tourism to be respectful of natural values and other cultural values; 
4) the continuation of the present efforts to identify and monitor particularly threatened species and habitats. This is already done through groups of experts and monitoring procedures such as the opening and maintenance of special files;

5) elaboration of a European strategy for the conservation of Nature/Biodiversity. (This can be done under the terms of Art. 2 and Art. 3, paragraph 1 of the Convention, which ask parties to take measures to maintain the populations of wild species at satisfactory levels and to promote policies for the conservation of wildlife and natural habitats);

6) protection of non-wild species, such as endangered crops, cultivars, rare livestock varieties, etc. Although these aspects are not contemplated now in the Convention, it would only require the will of the parties to develop conservation action in this field, mainly by way of recommendations and development and implementation of programmes;

7) more and better work in the field of exploitation of wildlife resources, such as those provided by game species or freshwater fish, that are subject to commercial exploitation or angling (Art. 7). These issues, prepared in collaboration with sport fishing and hunting organizations, would help to develop in practical terms the concepts of sustainable use of living resources;

8) an improved definition of the obligations on the control of the introduction of new genetic material in natural ecosystems (Art. 11, paragraph 2), including both nonnative species and Genetically Modified Organisms (GMOs);

9) effective action in the field of environmental education, dissemination of information, and promotion of public awareness of all aspects related to biodiversity conservation (as requested by Art. 3, paragraph 3 of the Bern Convention);

10) Promotion and coordination of research related to biodiversity conservation, as requested by Art. 11, paragraph $1 \mathrm{~b}$ of the Convention. This could take many forms, including the launching of specific research lines on priority subjects for conservation, or the creation of a Bern Convention label for research programmes with direct interest in the implementation of the Convention; and

11) strengthening of the cooperation aspects both with non-European parties (Burkina Faso, Senegal, and the other African countries invited to accede) and between Western and Eastern Europe. This could be done under the framework of Art. 1, paragraph 1 and Art. 11, paragraph la of the Convention.

The inclusion of new subjects and the re-enforcement of traditional ones in the work of the Bern Convention would strengthen its force, at the same time improving the regional implementation of many aspects of the Convention on Biological Diversity. Thus the Bern Convention has indeed a lot to offer to its parties, and it remains the main convention in the field of Nature and Biodiversity Conservation on the continental scale. The 'global' approach to conservation of biodiversity offered by the Convention would certainly help to give a more coherent European framework to intergovernmental activities in this field.

However, this Convention, or indeed any convention, will not succeed without the help and engagement of its parties. The Convention has been able to do in the last ten years an important amount of conservation work, mainly on European threatened wildlife, thanks to the financial support of the Council of Europe. It clearly needs now increased human and financial resources to carry out the above ambitious programme.

Eladio FERnANDEZ-Galiano Council of Europe F-67075 Strasbourg France.

\section{Basic Features of the St Petersburg Region and Relevant Environmental Problems: Project for Solution}

Tn various parts of the world, regional environmental proLlems are becoming more and more important (Gore, 1993; Kondratyev et al., 1993; Weizsäcker, 1994). The St Petersburg Region (SPR) is one of the most economically developed areas of Russia, being a huge interactive urban-rural complex involving a city having a population of 5 millions, with highly-developed industry and agriculture. The SPR is subject to a strong anthropogenic impact through the atmosphere and water systems (Fig. 1). The latter comprises the watershed of the Lake Ladoga-Neva River-Gulf of Finland system. This watershed is under the impact of the surrounding regions, and is a powerful source of pollution itself, especially for the Baltic Sea.

There is a high concentration of water-consuming industrial and agricultural units in the SPR, which are characteristic of a low (i.e. widely incomplete level of processing of raw materials into final products, in both the industrial and the agricultural sectors. This leads to the accumulation of large masses of waste, as well as to the pollution of water, soils, and the atmosphere, by toxic substances.

A specific feature of the SPR water system is the presence of various water-holding features - such as lakes, rivers, estuaries, the Gulf of Finland, and coastal zones which differ in the chemical composition of their waters, in the nature and scale of anthropogenic impacts, and further in their consequences. The acceleration of deforestation during recent years as a result of land privatization and the lack of its legal regulation, has led to the enhancement of soil erosion; it has also increased the runoff of phosphorus and nitrogen compounds, which has resulted in strong eutrophication of water-bodies. That is why the status of Lake Ladoga has become transformed from an oligotrophic to a mesotrophic (and sometimes eutrophic) state.

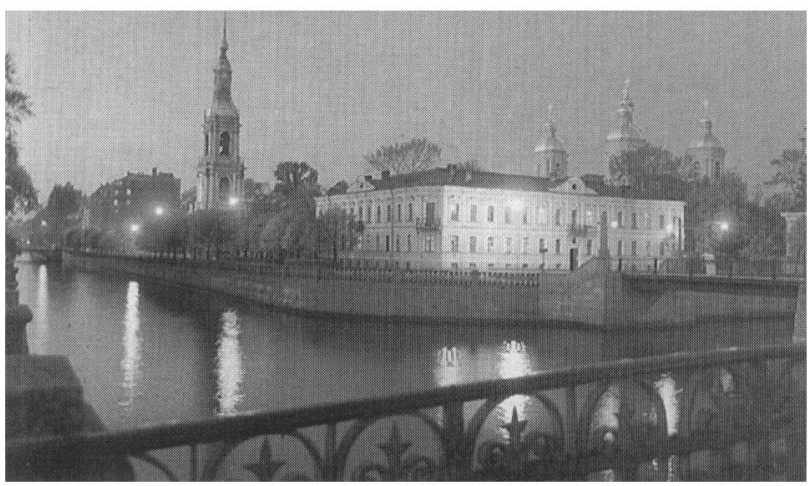

FIG. 1. Scene in St Petersburg, surely among the world's most magnificent waterside cities. 